Check for updates

Cite this: RSC Adv., 2018, 8, 40544

\title{
Effect of iron ion diffusion on the corrosion behavior of carbon steels in soil environment $\uparrow$
}

\author{
Ziheng Bai, ${ }^{\text {ab }}$ Kui Xiao, (D) *ab Pengfei Dong, ${ }^{\text {ab }}$ Chaofang Dong, (D) ab Dan Wei ${ }^{\mathrm{c}}$ \\ and Xiaogang $\mathrm{Li}^{\mathrm{ab}}$
}

The corrosion behavior of metal materials in soil environments has been intensively studied recently. Even so, the detailed corrosion mechanisms remain elusive, especially regarding the role of metal ions. In this study, we investigated the effect of ion diffusion on the corrosion processes of carbon steel via scanning electron microscopy (SEM), in situ laser Raman spectroscopy and scanning Kelvin probe (SKP). It was found that the $\mathrm{Fe}^{3+}$ diffusion was a key factor to the corrosion rate, as well as the formation of corrosion products. Typically, the corrosion products suppressed the diffusion of ions to the surface of carbon steels, and thus the cation diffusion coefficient played a significant role in formation processes of corrosion products, which furthermore affected the corrosion processes of the carbon steels.

Received 27th September 2018 Accepted 20th November 2018

DOI: $10.1039 / c 8 r a 08032 a$

rsc.li/rsc-advances surface was composed of $\mathrm{Fe}(\mathrm{II})$ oxide, Fe(III) oxide, and/or hydroxides, and the contribution of the Fe(II) species vanished when the potential of the film formation shifted into the passive domain. ${ }^{11}$ The corrosion of carbon steel in $\mathrm{NaCl}$ solution was investigated by using in situ Raman spectroscopy. ${ }^{12}$ The rust layer was composed of $\gamma$-FeOOH as an outer layer and $\mathrm{Fe}_{3} \mathrm{O}_{4}$ as an inner layer. ${ }^{13,14}$ The $\mathrm{FeOOH}$ was transformed into $\mathrm{Fe}_{3} \mathrm{O}_{4}$ when oxygen was insufficient, and the corrosion rate declined when the FeOOH layer became thicker and denser. ${ }^{14}$

However, most of these studies focused on the diffusion effect of compounds (i.e., $\mathrm{Fe}_{2} \mathrm{O}_{3}, \mathrm{Fe}_{3} \mathrm{O}_{4}, \mathrm{FeOOH}, \mathrm{FeCO}_{3}$, etc.), not $\mathrm{Fe}^{2+}$ and $\mathrm{Fe}^{3+}$ ions; these studies simultaneously focused on the physical and chemical properties of soil and failed to consider the soil as an electrolyte in their research. In this study, the electrochemical and corrosion behaviors of carbon steel in three different simulated soil environments, comprising kaolin, agar gel, and a simulated solution, were investigated by weight loss method, scanning electron microscopy (SEM), and in situ laser Raman spectroscopy as well as scanning Kelvin probe (SKP) method.

\section{Experimental methods}

\subsection{Materials and environmental media}

The chemical composition of carbon steel is (wt\%): C $0.16, \mathrm{Si}$ 0.20 , Mn 0.61, P 0.019, S 0.023 and Fe balance. The specimens for electrochemical measurement were machined to the dimensions $10 \mathrm{~mm} \times 10 \mathrm{~mm} \times 5 \mathrm{~mm}$. Then, the specimens were embedded in epoxy resin with an exposed working area of $1 \mathrm{~cm}^{2}$. The specimens for electrochemical measurements were sequentially ground with SiC paper from 320 grit to 2000 grit, polished with a $0.1 \mu \mathrm{m}$ alumina polishing powder, and then degreased with alcohol. 
Table 1 The composition of kaolin simulated soil medium

\begin{tabular}{llllll}
\hline Component & $\mathrm{NaCl}$ & $\mathrm{Na}_{2} \mathrm{SO}_{4}$ & $\begin{array}{l}\text { Deionized } \\
\text { water }\end{array}$ & Kaolin & $\begin{array}{l}\text { Quartz } \\
\text { sand }\end{array}$ \\
\hline Weight (g) & 14.61 & 3.551 & 200 & 250 & 43.72 \\
\hline
\end{tabular}

Table 2 The composition of agar gel simulated soil medium

\begin{tabular}{lllll}
\hline Component & $\mathrm{NaCl}$ & $\mathrm{Na}_{2} \mathrm{SO}_{4}$ & $\begin{array}{l}\text { Deionized } \\
\text { water }\end{array}$ & Agar gel powder \\
\hline Weight $(\mathrm{g})$ & 2.92 & 0.71 & 96.7 & 5
\end{tabular}

The compositions of the simulated soil media are listed in Tables 1 and 2. The composition of kaolin is $\mathrm{Al}_{2} \mathrm{O}_{3} \cdot \mathrm{SiO}_{2} \cdot \mathrm{H}_{2} \mathrm{O}$ (Table 1), which has a good aggregative state. Owing to the crystal structure, kaolin has extraordinary adsorption, dehydration, rehydration and ion exchange performance properties. Thus, kaolin is very close to a real soil environment. The quartz sand used here provides porosity. The agar gel can change into a colloid when it absorbs 20 times its volume of water. Agar gel can be dissolved in hot water but not cold water, and the solution remains a liquid at $42{ }^{\circ} \mathrm{C}$ but coagulates into a colloid at $37^{\circ} \mathrm{C}$. The agar gel colloid has the properties of solidification and stability. To keep the concentration of $\mathrm{Cl}^{-}$and $\mathrm{SO}_{4}{ }^{2-}$ in the solution uniform (mass fraction), a defined ratio of salts to agar was prepared, and the mixture was dissolved at $90{ }^{\circ} \mathrm{C}$ after being well mixed, turning into a colloid after cooling. The proportions are listed in Table 2.

To eliminate the effect of anions in the aqueous solution on corrosion, the simulated solution containing $\mathrm{Cl}^{-}\left(0.5 \mathrm{~mol} \mathrm{~L}^{-1}\right)$ and $\mathrm{SO}_{4}{ }^{2-}\left(0.05 \mathrm{~mol} \mathrm{~L}{ }^{-1}\right)$ was prepared by using $\mathrm{FeCl}_{3}$ and $\mathrm{FeSO}_{4}$, respectively. In addition, the ions were balanced by $\mathrm{NaCl}$ and $\mathrm{Na}_{2} \mathrm{SO}_{4}$. The concentration of $\mathrm{Fe}^{3+}$ was changed from $0 \mathrm{~mol} \mathrm{~L}{ }^{-1}$ to $0.005 \mathrm{~mol} \mathrm{~L}^{-1}, 0.01 \mathrm{~mol} \mathrm{~L}^{-1}$, and $0.05 \mathrm{~mol} \mathrm{~L}^{-1}$. The electrochemical samples of carbon steel were prepared by electrochemical tests in the prepared and oxygen-free solution.

\subsection{Weight loss method}

The prepared samples were immersed in the simulated media environments. The samples were taken out after being immersed or buried for $0 \mathrm{~h}, 24 \mathrm{~h}, 72 \mathrm{~h}$ and $128 \mathrm{~h}$. The surface corrosion products were removed using an acid solution $(500 \mathrm{~mL} \mathrm{HCl}+500 \mathrm{~mL}$ deionized water $+4 \mathrm{~g}$ hexamethylenetetramine). The acid solution was the standard acid solution used to remove the rust on carbon steel, which is, however, not harmful to carbon steel substrates; to obtain the weight $G_{1}$, samples were rinsed with clean water after pickling, soaked in ethanol, dried in a cool air flow, and kept in the dryer. The samples were weighed (with an accuracy of $0.1 \mathrm{mg}$ ), and the corrosion weight loss, $W$, was calculated by the following equation:

$$
W=\frac{G_{0}-G_{1}}{2 \times(a b+b c+a c)}
$$

where $W$ is the weight loss $\left(\mathrm{g} \mathrm{cm}^{-2}\right), G_{0}$ is the sample's original weight $(\mathrm{g}), G_{1}$ is the sample's weight after removing the corrosion products, and $a, b$, and $c$ are the length, width and thickness $(\mathrm{mm})$ of the samples. Weight loss data were the average of the parallel samples.

\subsection{The analyses of corrosion products}

The SEM morphologies of the corrosion products were observed via an FEI Quanta 250 scanning electron microscope. A JYHR800 micro-Raman spectrometer was used to detect the composition of the corrosion products. Raman excitation was performed at a wavelength of $532 \mathrm{~nm}$, a laser power of $1 \mathrm{~mW}$ and a laser spot diameter of $3 \mu \mathrm{m}$. The data collection time was $100 \mathrm{~s}$.

\subsection{Ion diffusion rate test}

Fig. 1 shows CAD diagrams of the diffusion coefficient measuring device. The device consisted of a Plexiglass box which was divided into two reservoirs and a central cavity. A piece of semipermeable membrane was stuck on one side of the cavity using silicone. The cavity was filled with agar gel colloid or kaolin after the silicone had been air-dried. Then, on the other side, it was also sealed by silicone and the other semipermeable membrane in the same way as the former one. The equipment was air-dried and washed with deionized water.

A $1 \mathrm{~L}$ volume of deionized water was poured into the reservoir on one side of the Plexiglass box as the original receptor solution, and $1 \mathrm{~L}$ of a $0.01 \mathrm{~mol} \mathrm{~L}^{-1} \mathrm{FeCl}_{3}$ benchmark solution was poured into the other side of the box as the donor solution. The box was placed horizontally and sealed with plastic wrap to prevent evaporation. The ion-exchange membrane adopted in this experiment was JAM-1 homogeneous cation exchange membrane that was made of aromatic hydrocarbons, double vinyl compounds and linear polymers. The total number of iron ions was determined by means of phenanthroline spectrophotometry.

The test instrument used in the iron standard curve and spectrophotometric test was a Hitachi U-3900H spectrophotometer; the measurement wavelength range was 400-600 nm and the molar absorption coefficient was $1.1 \times 10^{4} \mathrm{~L} \mathrm{~mol}^{-1} \mathrm{~cm}$. The simulated solution was prepared by a prescribed procedure.

\subsection{Surface potential analysis of the samples}

The surface potential of metal with corrosion products in atmospheric environment can be detected using a scanning Kelvin probe (SKP), which has a linear relationship with corrosion potential. Thus, the SKP can reflect the changes of corrosion potential in corrosion processes, and furthermore investigate the corrosion behavior. The SKP test was performed using the SKP module of an M370 scanning microelectrochemical workstation manufactured by Princeton Applied Research. The scanning Kelvin probe test system was calibrated using a saturated calomel electrode (SCE) before the testing. The test setup is shown in Fig. 2, where the test area is marked with a white square. 
b

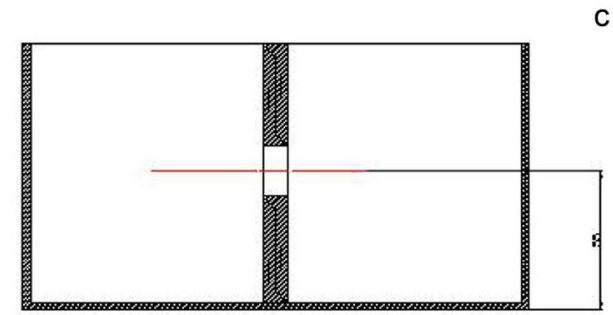

a

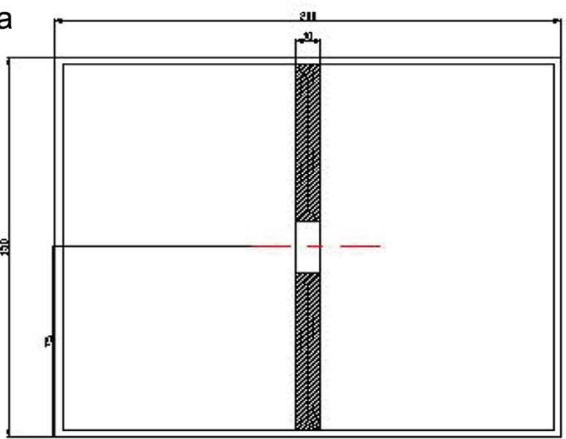

C

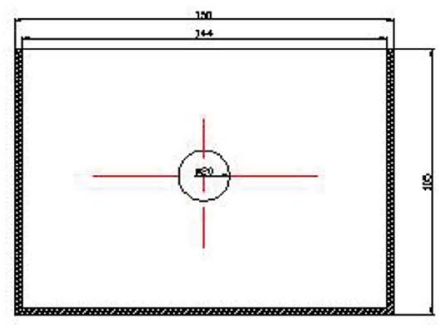

Fig. 1 CAD three-view of the diffusion coefficient measuring device, (a) front view, (b) side front with the membrane and (c) vertical view (from left to right).

To determine the test location, we moved the probe down to the lower left corner of the sample surface as a reference point (red dot in Fig. 2), and then moved it $3000 \mu \mathrm{m}$ in the $Y+$ direction. Next, we set the parameters, and then moved the probe $1000 \mu \mathrm{m}$ in the $X$-direction for the origin of the SKP plane scan. To make sure that each test was located at that point for an in situ measurement, we set the test parameters as follows: the scanning area was $2000 \mu \mathrm{m} \times 1000 \mu \mathrm{m}$, the step length was 50 $\mu \mathrm{m}$, the probe vibration amplitude was $30 \mu \mathrm{m}$, and the average distance between the probe and the sample surface was controlled within $100 \mu \mathrm{m}$.

The test environment was saturated water $(\sim 20 \%)$ kaolin; the ingredients are shown in Table 1. To maintain a constant moisture content, the kaolin was sealed with plastic wrap after each test was completed. Every 24 hours, the kaolin was weighed on a balance and water was added dropwise to maintain a constant weight.

\section{Results}

\subsection{Weight loss curves in different medium environments}

The measurement of weight loss of the carbon steel in three different media is shown in Fig. 3. The weight loss in solution increased with increasing experimental time. For the fresh surface of the sample in the early stage, the surface metal continuously dissolved into the simulated solution; however, the early corrosion products provided a protective effect in suppressing the corrosion process formed on the surface, and thus the corrosion rate slowed down gradually with the formation of a rust layer. However, as the corrosion products became loose and dissolvable in the solution, the protective effect on the matrix was weakened, and the corrosion rate increased again. Finally, the corrosion rate gradually reduced to a fixed value. This situation is similar to the weight loss trend of mild steel in sandy, clay and loamy soil environments. ${ }^{15}$ It was obvious that the cations generated on the surface in the kaolin and agar gel

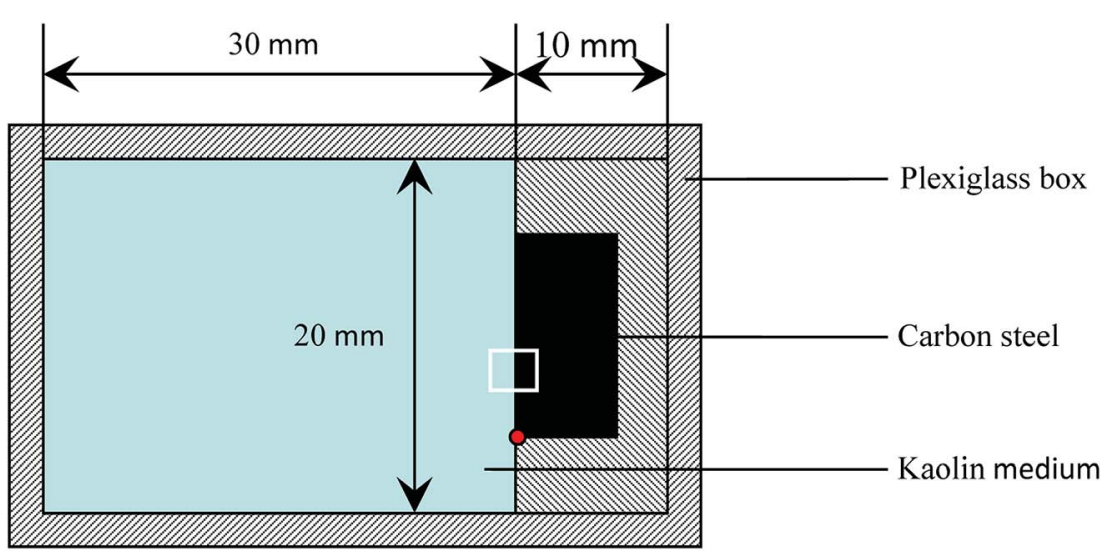

Fig. 2 Schematic of the SKP test of carbon steel in kaolin medium, where the test area is marked with a white square. 


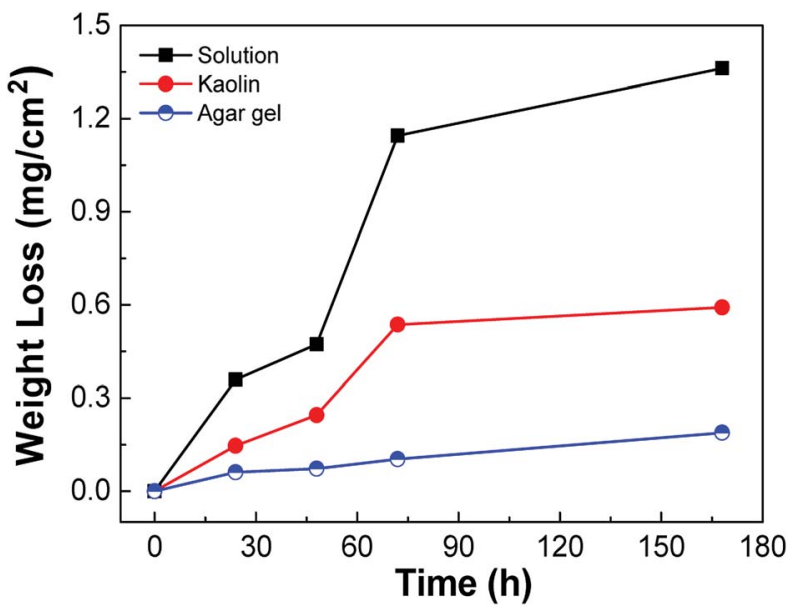

Fig. 3 The weight loss curves of samples in three different media with different times.

cannot diffuse as readily as those in the solution, and therefore, the corrosion products were not as loose as those in the solution. When the corrosion products accumulated to a certain threshold, the corrosion rate rapidly decreased.

\subsection{Corrosion product analysis}

Fig. 4 shows the morphology of the corrosion products in three different media. In Fig. 4(a), the rust grew relatively smoothly and perpendicular to the surface. The outer rust layer was smooth, and needle-like products were observed. In Fig. 4(b), the rust grew along the surface. Owing to its growth restriction in the perpendicular direction, the homogeneity and crystallization of the rust were enhanced. Fig. 4(c) shows the growth of rust intertwined with the agar gel, in which flake-like crystallites can be observed only in a localized area. Combined with the kinetic weight loss curves, the corrosion rate in the simulated solution was the highest, followed by that in kaolin and, lastly, that in agar gel. This could be explained by the structure of the different corrosion products in the media. The structure of the outer-layer corrosion products generated in solution was loose, and could not restrain corrosive species such as anions or oxygen from permeating into the substrate ${ }^{16}$ thus, the corrosion rate in the solution environment was the highest. Although the corrosion products formed in kaolin were more intensive, the blocking effect of its petal-like rust layer was less than that in agar gel, and therefore, the degree of corrosion in kaolin was more severe than that in agar gel.

The permeability of a soil is determined by its structure and particle size, ${ }^{17}$ and it can affect the movement rate of gases and liquids in the soil. The retention ability of small particles, such as slime, is much higher than that of large-sized particles, such as sand..$^{18}$ Low-permeability soils can absorb underground water through capillary action, and thus water saturation occurs in some part, which becomes a barrier against the movement of air. In the case of kaolin, owing to the fact that its conglutination on the metal surfaces was strong, its expansion or contraction under hydration and ion exchange processes could introduce mechanical forces on material surfaces, which finally caused damage to the metal surfaces. Therefore, the corrosive ingredients in the solution could arrive at the metal surfaces through the cracks and ultimately led to the accelerating of
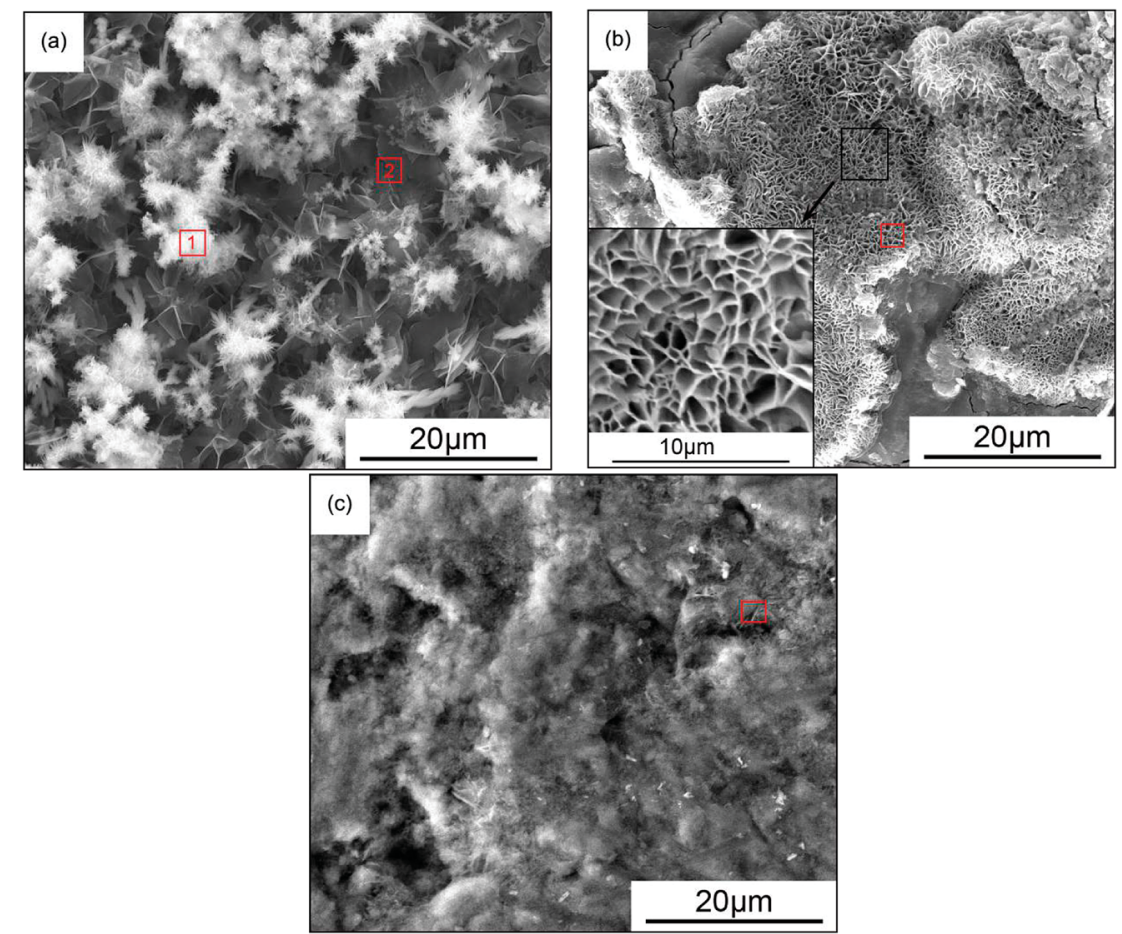

Fig. 4 The SEM images of the corrosion products of carbon steel in three different simulated soil media. (a) Simulated solution for $24 \mathrm{~h}$, (b) kaolin for $168 \mathrm{~h}$, (c) agar gel for $168 \mathrm{~h}$. 


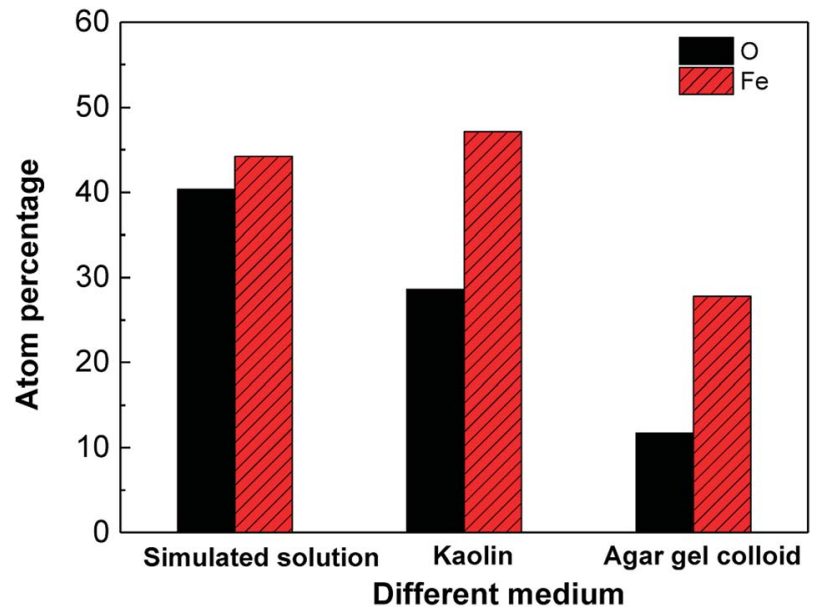

Fig. 5 The ratio of the elements iron and oxygen in the corrosion products in different media.

corrosion processes. A similar phenomenon was observed in soil corrosion of X70 pipeline steel in a red clay soil environment. ${ }^{19}$ However, because of the small particles in kaolin, the diffusion ability of the ions was less, and thus, the corrosion products were able to adhere to the surface of the specimen more easily, and additionally inhibit the corrosion processes. The ratio (atomic percentage) of the elements iron and oxygen in the red squares area of Fig. 4 is shown in Fig. 5. The percentage of iron in the corrosion products in kaolin was higher than that in agar gel, and the medium was responsible for this: based on the test of the diffusion rate, the diffusion rate of iron in agar gel was faster than that in kaolin, and hence only a small amount of iron remained on the surfaces and then formed corrosion products.

Fig. 6 shows the micro-Raman spectroscopy of the various corrosion products. The Raman spectrum of the corrosion products formed on the carbon steel surface in the simulated solution is shown in Fig. 6(a). According to the values for Raman peaks of iron compounds given in previous studies, ${ }^{\mathbf{2 0 , 2 1}}$ the corrosion products could be identified as follows. The peaks appearing at 250, 526, 651, 1050 and $1304 \mathrm{~cm}^{-1}$ are the characteristic peaks of $\gamma-\mathrm{FeOOH}$, while the peaks at 310 and $341 \mathrm{~cm}^{-1}$ are the characteristic peaks of $\gamma-\mathrm{Fe}_{2} \mathrm{O}_{3}$. In addition, a small amount of $\alpha-\mathrm{Fe}_{2} \mathrm{O}_{3}$ is also indicated in the spectrum, with the corresponding peaks at 225 and $300 \mathrm{~cm}^{-1}$. The Raman spectrum of the corrosion products formed in kaolin is shown in Fig. 6(b). The peaks at 298, 399, 481, 554 and $1002 \mathrm{~cm}^{-1}$ are the characteristic peaks of $\alpha-\mathrm{FeOOH}$, while those at 222, 244, $298,501,615$, and $1318 \mathrm{~cm}^{-1}$ are the characteristic peaks of $\alpha$ $\mathrm{Fe}_{2} \mathrm{O}_{3}$. In addition, the two peaks at 550 and $675 \mathrm{~cm}^{-1}$ also indicate that a small amount of $\mathrm{Fe}_{3} \mathrm{O}_{4}$ appeared in the corrosion products. The Raman spectrum of the corrosion products generated in agar gel is shown in Fig. 6(c). The peaks at 50, 380, $526,651,1050$ and $1304 \mathrm{~cm}^{-1}$ are the characteristic peaks of $\gamma$ $\mathrm{FeOOH}$, the double peaks at 550 and $675 \mathrm{~cm}^{-1}$ suggest that there was a small amount of $\mathrm{Fe}_{3} \mathrm{O}_{4}$, and the peaks at 1400$1600 \mathrm{~cm}^{-1}$ are associated with the carbon in the agar gel.

From the differences among the three media, it could be found that the corrosion products in kaolin were mainly $\alpha$ - (a)

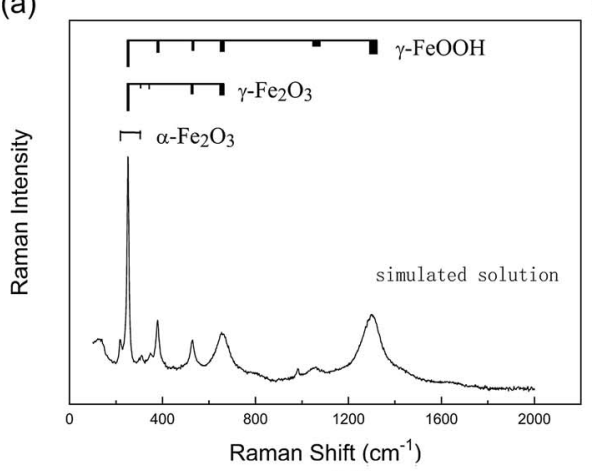

(b)

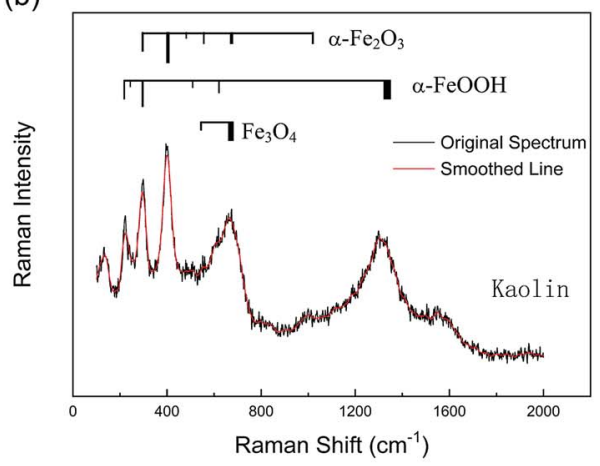

(c)

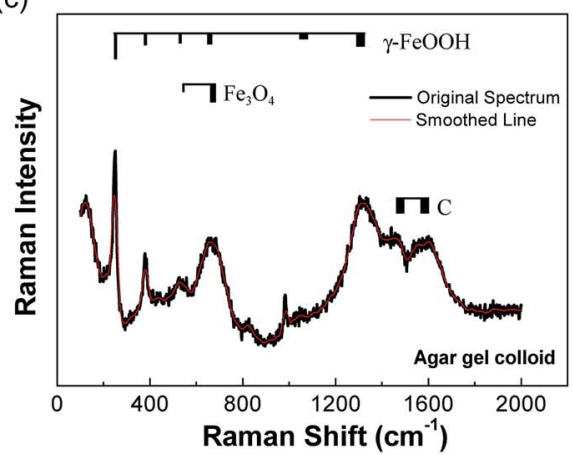

Fig. 6 Raman spectra of the corrosion products of carbon steel in three different diffusion media after 168 h: (a) simulated solution, (b) kaolin, and (c) agar gel. 
(a)

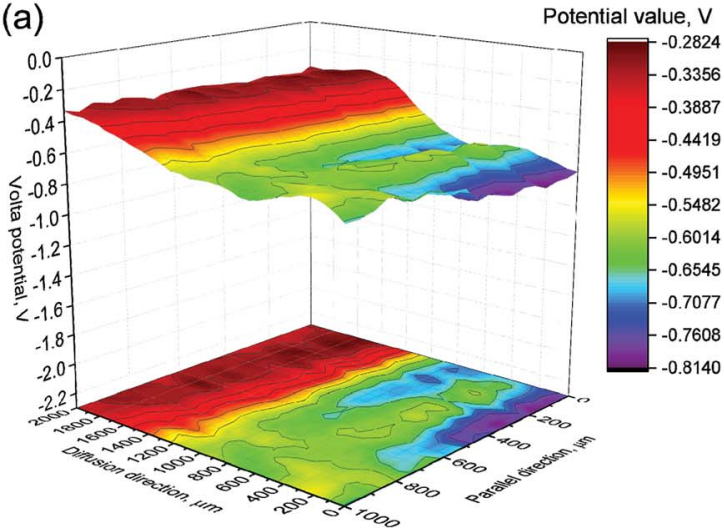

(c)

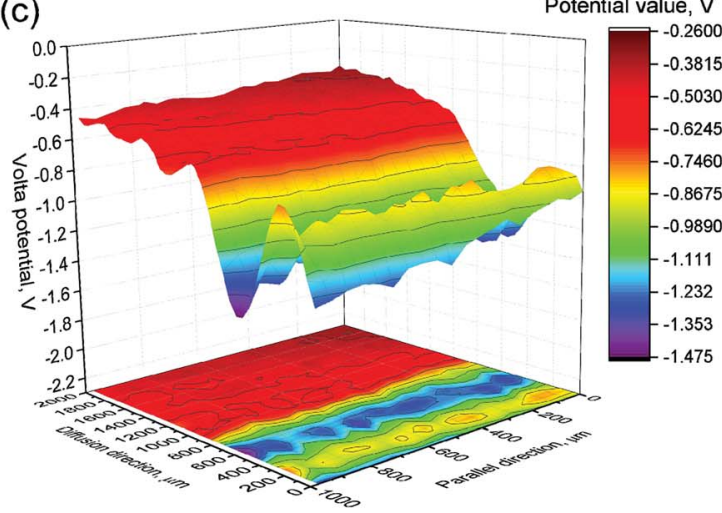

(b)

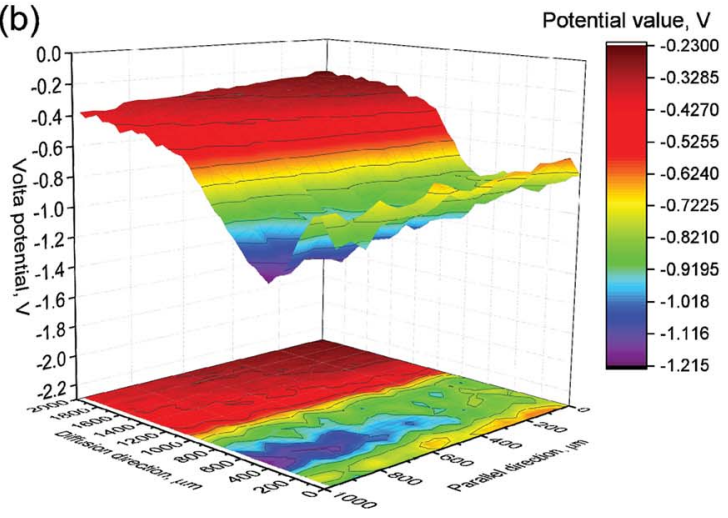

(d)

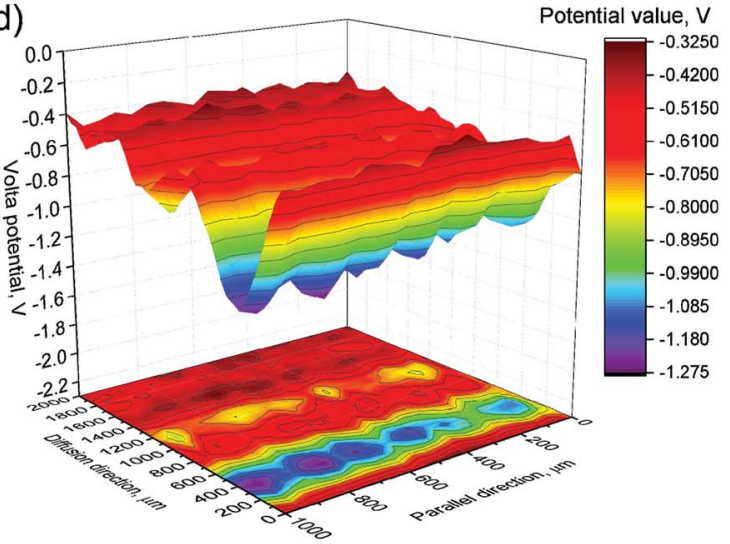

Fig. 7 Potential distribution diagrams of SKP test of carbon steels in kaolin simulated medium for different times: (a) $0 \mathrm{~h}$, (b) $24 \mathrm{~h}$, (c) $72 \mathrm{~h}$ and (d) $168 \mathrm{~h}$.

FeOOH and $\alpha-\mathrm{Fe}_{2} \mathrm{O}_{3}$, while in the simulated solution and agar gel, they were mainly $\gamma$-FeOOH and $\mathrm{Fe}_{3} \mathrm{O}_{4}$. Typically, the formation of corrosion products of carbon steels and their transformation were different in different media. Previous research $^{21}$ had demonstrated that in neutral environments, the primary corrosion product was $\gamma-\mathrm{FeOOH}$, which gradually transformed into $\gamma-\mathrm{Fe}_{2} \mathrm{O}_{3}$, which was more stable. Because the crystal structure of $\mathrm{FeOOH}$ was poor, the $\mathrm{FeOOH}$ tended to transform into $\mathrm{Fe}_{2} \mathrm{O}_{3}$, and the formula for this transformation is

$$
2 \mathrm{FeOOH} \rightarrow \mathrm{Fe}_{2} \mathrm{O}_{3}+\mathrm{H}_{2} \mathrm{O}
$$

Formula (2) can be regarded as a dehydration reaction. The concentration of $\mathrm{Fe}_{2} \mathrm{O}_{3}$ was low in the simulated solution and in the agar gel medium. And since they have better water absorption, $\gamma$-FeOOH could convert into $\alpha$-FeOOH or $\gamma-\mathrm{Fe}_{2} \mathrm{O}_{3}$ at first, and then the $\gamma-\mathrm{Fe}_{2} \mathrm{O}_{3}$ be transformed into $\alpha-\mathrm{Fe}_{2} \mathrm{O}_{3}{ }^{22}$ The corrosion products $\gamma$-FeOOH and $\mathrm{Fe}_{3} \mathrm{O}_{4}$ that were detected in corrosion products of low carbon steel in $0.01 \mathrm{M} \mathrm{NaCl}$ solution mainly came from the passivity of iron. ${ }^{23}$

\subsection{SKP test in soil medium}

In this section, the potential change of the cross section of sample-interface (corrosion products) - kaolin of Q235 carbon steel in a soil environment was studied by scanning Kelvin probe (SKP). This was used to detect the influence of ions and the formation of corrosion products. The SKP method has been used in the study of corrosion behaviors of metals. ${ }^{24,25}$ The in situ measurements of the marked locations of the samples in Fig. 2 were taken at $0 \mathrm{~h}, 24 \mathrm{~h}, 72 \mathrm{~h}$ and $168 \mathrm{~h}$ respectively, and the test results are shown in Fig. 7 as unified $z$-axis coordinate contour maps.

The potential of the cross section of the kaolin and metal specimens was different (from Fig. 7(a)). The light blue area in Fig. 7(b), which could be considered as a mixture of corrosion products and kaolin, possibly caused by the edge effect of the metal sample. The darker color areas in Fig. 7(b-d) indicated the diffusion of metal ions, and illustrated the diffusion of ions with time prolonged. The figure also indicated that the ion diffusion areas continued to shrink, and simultaneously the transition area became wider. This phenomenon occurred because the iron ions continued to take part in the reactions and generated iron oxide or oxy-hydroxide compounds.

Moreover, the following information can be obtained from Fig. 7. First, along the $x$-axis, the potential mainly consisted of the following three regions: the higher potential region which corresponded to the metal sample side, the lower potential region which was associated with the kaolin side, and the middle region which reflected the transition zone. The higher potential of the specimen on the metal side after 24 hours represented the formation of the corrosion products, and this region gradually expanded along the $y$-axis with prolonged 


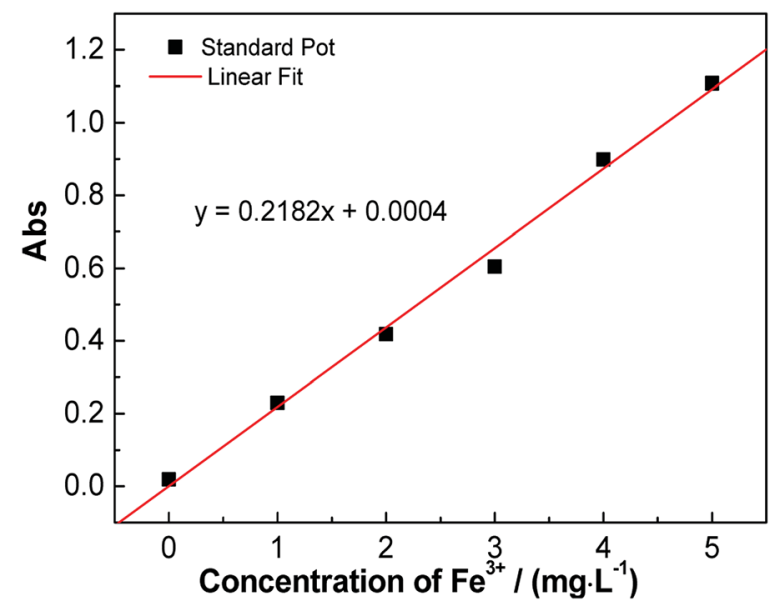

Fig. 8 Iron standard curve measured by phenanthroline spectrophotometry, where the molar concentration of $\mathrm{Fe}^{3+}$ is $8.39 \times$ $10^{-4} \mathrm{~mol} \mathrm{~L}^{-1}$ after the conversions.

reaction time. The potential distribution of the kaolin side gradually became disperse, and a point of extremely high value appeared. This phenomenon indicated that the diffusion of ions and the corrosion products in the kaolin was not uniform and was different in different localized regions. In a soil environment, owing to the complexity of the soil structure and the differences of physicochemical properties, metal ions and the related corrosion products are also preferentially diffused along voids with high porosity or moisture after the metal is dissolved.

\subsection{Phenanthroline spectrophotometry}

Fig. 8 shows the standard curve of iron measured by the phenanthroline spectrophotometry (ISO 6685-1982). It was fitted by a linear standard curve equation as follows, where $y$ is absorption and $x$ is the concentration of $\mathrm{Fe}^{3+}$ :

$$
y=0.2182 x+0.0004
$$

The ion diffusion rate example in kaolin was calculated as an example. The measured absorption of the water sample after $48 \mathrm{~h}$ was $y=0.103$; thus, a value of $x=0.470\left(\mathrm{mg} \mathrm{L}^{-1}\right)$ was obtained after substitution into the standard curve equation (with a 100-fold diluted solution). The total number $(n)$ of iron ions in the receptor solution $(1 \mathrm{~L})$ could be calculated as follows:

$$
n=\frac{0.470 \mathrm{mg} \mathrm{L}^{-1} \times 100 \times 1 \mathrm{~L}}{56 \times 10^{3} \mathrm{mg} \mathrm{mol}^{-1}}=8.39 \times 10^{-4} \mathrm{~mol}
$$

Therefore, the average diffusion rate $\left(\nu_{\mathrm{d}}\right)$ of iron in the kaolin medium in the first 2 days was:

$$
v_{\mathrm{d}}=\frac{8.39 \times 10^{-4} \mathrm{~mol} \times 1 \mathrm{~cm}^{2}}{48 \times 3600 \mathrm{~s}}=4.86 \times 10^{-9} \mathrm{~mol} \mathrm{~cm}^{-2} \mathrm{~s}^{-1}
$$

From Fick's first law, the relationship between the average diffusion rate $\left(\nu_{\mathrm{d}}\right)$ and the average concentration gradient was as follows, where $\mathrm{c}$ is the concentration of ions, $x$ is the length and $D$ is the diffusion coefficient:

$$
\begin{gathered}
v_{\mathrm{d}}=-D\left(\frac{\Delta c}{\Delta x}\right) \\
D=-\frac{v_{\mathrm{d}}}{\left(\frac{\Delta c}{\Delta x}\right)}=-\frac{4.86 \times 10^{-9} \mathrm{~mol} \mathrm{~cm}^{2} \mathrm{~s}^{-1}}{\frac{0.01 \mathrm{~mol} \mathrm{~L}^{-1}}{1 \mathrm{~cm}}} \\
=-4.86 \times 10^{-4} \mathrm{~cm}^{2} \mathrm{~s}^{-1}
\end{gathered}
$$

In the early stage of the diffusion, compared with the donor solution, the ion concentration in the receptor solution was very low; therefore, $\Delta c$ could be approximated as $0.01 \mathrm{~mol} \mathrm{~L}^{-1}$, while $\Delta x$ was the length of the diffusion cavity, which was $1 \mathrm{~cm}$. The diffusion coefficient $\left(D=-4.86 \times 10^{-4} \mathrm{~cm}^{2} \mathrm{~s}^{-1}\right)$ in kaolin medium was calculated using eqn (7). This value was larger than that measured in Fricke gel dosimeters (where $D$ is around $\left.-1.81 \times 10^{-6} \mathrm{~cm}^{2} \mathrm{~s}^{-1}\right),{ }^{26,27}$ maybe due to the fact that $\nu_{\mathrm{d}}$ in kaolin medium was larger than that in agar gel colloid dosimeters. Similarly, the diffusion rate and coefficient in agar gel medium could be calculated, and the results are listed in Table 3. The diffusion rate of $\mathrm{Fe}^{3+}$ in the agar gel was higher than that in kaolin.

Combined with Fig. 3, we further concluded that the diffusion rate of ions was fast, and therefore, rust could not accumulate on the matrix. Although rust was formed, the structure was still very loose and its protection ability was very poor. For the comparison between agar gel colloid and kaolin, the inflection point of the weight loss curve of kaolin was more obvious, which indicated that the ability of the corrosion products to suppress corrosion processes was more useful.

\subsection{The models of corrosion mechanisms}

In general, corrosion processes consist of two basic reactions, the anodic and cathodic reactions, the cathodic one in the corrosion of iron is as follows, which is also the first step in the sequence of corrosion processes of iron:

Table 3 The concentration of iron ions in different media

\begin{tabular}{llll}
\hline Diffusion medium & $\begin{array}{l}\text { Diffusion capacity } \\
(\mathrm{mol})\end{array}$ & $\begin{array}{l}\text { Diffusion rate } \\
\left(\mathrm{mol} \mathrm{cm}^{-2} \mathrm{~s}^{-1}\right)\end{array}$ & $\begin{array}{l}\text { Diffusion coefficient } \\
\left(\mathrm{cm}^{2} \mathrm{~s}^{-1}\right)\end{array}$ \\
\hline Kaolin & $8.39 \times 10^{-4}$ & $4.86 \times 10^{-9}$ & $-4.86 \times 10^{-4}$ \\
Agar gel colloid & $2.50 \times 10^{-3}$ & $1.45 \times 10^{-8}$ & $-1.45 \times 10^{-3}$
\end{tabular}




$$
\mathrm{Fe} \rightarrow \mathrm{Fe}^{2+}+2 \mathrm{e}^{-}
$$

Typically, the $\mathrm{OH}^{-}$mainly comes from the anodic action in the electrochemical reaction that is associated with the corrosion processes, and the anodic action in a neutral environment is:

$$
\mathrm{O}_{2}+2 \mathrm{H}_{2} \mathrm{O}+4 \mathrm{e}^{-} \rightarrow 4 \mathrm{OH}^{-}
$$

Owing to the tiny interstices among the kaolin particles which had a diameter about 2-20 $\mu \mathrm{m}$, thin water films occurred on the surfaces of specimens. When $\mathrm{Fe}^{2+}$, the product of reaction (8), occurred in these thin liquid films, the diffusion step began as the result of the concentration gradient, and the direction was from the thin liquid films to the interstices owing to the dissolvability of $\mathrm{Fe}^{2+}$. In the aqueous environment, reaction (8) occurred on the surface of specimens and the ions diffused from the surface to the solution. Thus, the cathodic reaction proceeded continuously and the corrosion products formed (eqn (10)-(12)).
When the samples were immersed in the simulated solution or simulated soil environments, the electrode reaction occurred at the interface between the matrix and the solution or liquid films (eqn (8) and (9)), and $\gamma$-FeOOH gradually covered the surfaces of the specimens (10)-(12).

$$
\begin{gathered}
\mathrm{Fe}^{2}+2 \mathrm{OH}^{-} \rightarrow \mathrm{Fe}(\mathrm{OH})_{2} \\
2 \mathrm{Fe}(\mathrm{OH})_{2}+\mathrm{O}_{2}+\mathrm{H}_{2} \mathrm{O} \rightarrow 2 \mathrm{Fe}(\mathrm{OH})_{3} \\
\mathrm{Fe}(\mathrm{OH})_{3} \rightarrow \gamma-\mathrm{FeOOH}+\mathrm{H}_{2} \mathrm{O}
\end{gathered}
$$

Because the $\gamma$-FeOOH had poor crystal structure, there was a tendency for it to transform into $\mathrm{Fe}_{2} \mathrm{O}_{3}$ as shown in formula (13). Thus, $\gamma$-FeOOH and $\mathrm{Fe}_{2} \mathrm{O}_{3}$ were detected in Raman analysis of the simulated solution.

$$
2 \gamma-\mathrm{FeOOH} \rightarrow \mathrm{Fe}_{2} \mathrm{O}_{3}+\mathrm{H}_{2} \mathrm{O}
$$
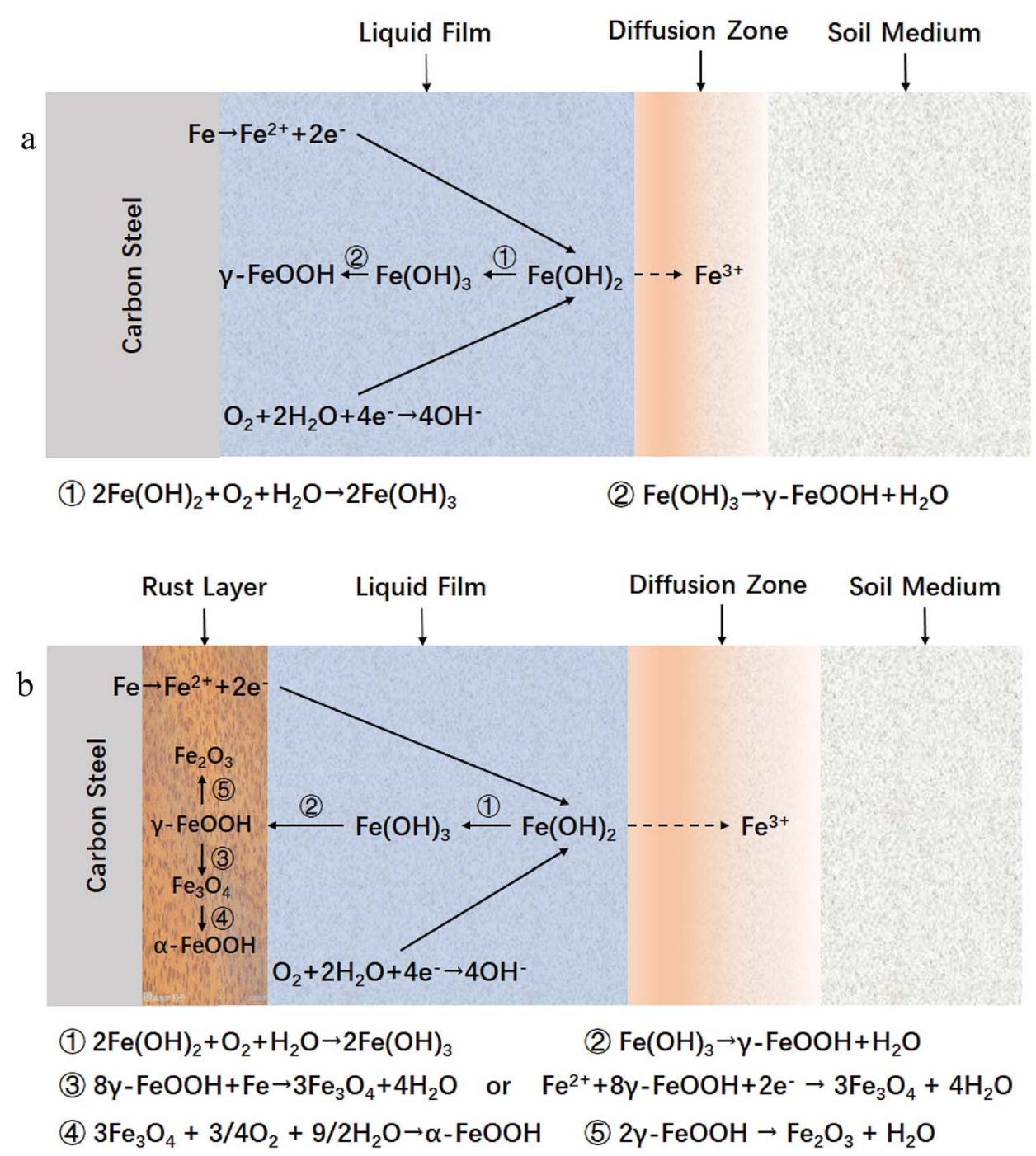

Fig. 9 Corrosion products and the iron ion diffusion models of carbon steel, (a) the initial stage in corrosion processes and (b) development stage associated with the supplement of oxygen. 
However, with lower diffusion rates of ions in agar and kaolin, the $\mathrm{Fe}^{2+}$ was more easily accumulated on the surface area of the carbon steel, and thus more corrosion products were easily formed. Therefore, an insufficient $\mathrm{O}_{2}$ environment occurred because of obstruction by the corrosion product layer. It was found that $\mathrm{Fe}_{3} \mathrm{O}_{4}$ formed more easily when the dissolved oxygen was insufficient; ${ }^{10}$ the relevant reactions are shown in formulas (14) and (15). ${ }^{20}$ And this interpretation is consistent with Evans's theory, ${ }^{28,29}$ which explained the mechanism during the dehydration process with the formation of the corrosion products of carbon steel. Thus, the corrosion products in agar consisted of $\gamma$-FeOOH and a little $\mathrm{Fe}_{3} \mathrm{O}_{4}$ :

$$
8 \gamma-\mathrm{FeOOH}+\mathrm{Fe} \rightarrow 3 \mathrm{Fe}_{3} \mathrm{O}_{4}+4 \mathrm{H}_{2} \mathrm{O}
$$

or

$$
\mathrm{Fe}^{2+}+8 \gamma-\mathrm{FeOOH}+2 \mathrm{e}^{-} \rightarrow 3 \mathrm{Fe}_{3} \mathrm{O}_{4}+4 \mathrm{H}_{2} \mathrm{O}
$$

Furthermore, when the supply of oxygen was more insufficient, the location where the electrode reaction went on gradually migrated from the interface between the matrix and liquid films to the interface between the inner and outer rust layers. Thus, the $\mathrm{Fe}_{3} \mathrm{O}_{4}$ was oxidized to form $\alpha$-FeOOH according to formula (16), and so $\alpha-\mathrm{FeOOH}$ was detected in the corrosion products in kaolin owing to the lower diffusion rate.

$$
3 \mathrm{Fe}_{3} \mathrm{O}_{4}+3 / 4 \mathrm{O}_{2}+9 / 2 \mathrm{H}_{2} \mathrm{O} \rightarrow \alpha-\mathrm{FeOOH}
$$

Moreover, based on the SKP results above, the diffusion models of the iron ions and corrosion products of carbon steel are shown in Fig. 9. The models include a carbon steel substrate, a corrosion product layer with a good crystalline structure containing oxide and oxy-hydroxide, a diffusion zone composed of a mixture of corrosion products and soil medium, and an outer soil medium zone.

\section{Conclusions}

(1) The formation of the corrosion products was determined by the cation diffusion coefficient, which furthermore affected the corrosion processes of the carbon steel.

(2) The corrosion products in the three different environments were different. The analyses of the corrosion products indicated that the corrosion products in kaolin were mainly $\alpha$ $\mathrm{FeOOH}$ and $\alpha-\mathrm{Fe}_{2} \mathrm{O}_{3}$; however, in agar gel, they were $\gamma$-FeOOH. From the analysis of morphology, the corrosion products in agar gel were densest, which offered a protective effect to the carbon steel, and the protection was stronger than that of the "petal-like" corrosion products in kaolin medium;

(3) The SKP analysis of Q235 carbon steel in a simulated soil environment indicated that the changes in potential of the cross section at each interface could clearly reflect the beginning of the corrosion processes in the soil environment. And the variation and distribution of the potential value in the kaolin zone reflected the state of diffusion of the metal ions. As time passed, the diffusion zone and rust layer became obviously wider.

\section{Conflicts of interest}

There are no conflicts to declare.

\section{Acknowledgements}

This work was supported by the National Key Research and Development Program of China (Grant No. 2017YFB0304602), the National Basic Research Program of China (973 Program, No. 2014CB643300), the National Natural Science Foundation of China (No. 51271032), and the National Environment Corrosion Platform (NECP).

\section{References}

1 Z. Wang, X. U. Chun and X. Dong, Chin. J. Chem. Eng., 2008, 16, 99.

2 S. Handley-Sidhu, N. D. Bryan, P. J. Worsfold, D. J. Vaughan and F. R. Livens, Chemosphere, 2009, 77, 1434.

3 S. Tang, X. Wang, S. Liu, H. Yang, Y. F. Xie and X. Yang, Chemosphere, 2017, 178, 119.

4 X. Li, D. Zhang, Z. Liu, Z. Li, C. Du and C. Dong, Nature, 2015, 527, 441.

5 B. Hou, X. Li, X. Ma, C. Du, D. Zhang, M. Zheng, W. Xu, D. Lu and F. Ma, Npj Materials Degradation, 2017, 1, 4.

6 X. H. Nie, X. G. Li, C. W. Du, Y. Z. Huang and H. Du, J. Raman Spectrosc., 2009, 40, 76.

7 F. Xie, D. Wang, C. X. Yu, Y. Zhang and M. Wu, Int. J. Electrochem. Sci., 2017, 12, 9565.

8 P. J. Han, R. Z. Xie, N. M. Lin and B. He, Int. J. Electrochem. Sci., 2016, 11, 9491.

9 J. Skopp and D. McCallister, Soil Sci. Soc. Am. J., 2016, 11, 617.

10 Y. H. Huang and T. C. Zhang, Water Res., 2005, 39, 1751.

11 S. J. Oh, D. C. Cook and H. E. Townsend, Hyperfine Interact., 1998, 112, 59.

12 X. Zhang, S. Yang, W. Zhang, H. Guo and X. He, Corros. Sci., 2014, 82, 165.

13 P. Colomban, S. Cherifi and G. Desper, J. Raman Spectrosc., 2008, 39, 881.

14 K. Xiao, C. F. Dong, X. G. Li and F. W. J. Wang, J. Iron Steel Res. Int., 2008, 15, 428.

15 E. E. Oguzie, I. B. Agochukwu and A. I. Onuchukw, Mater. Chem. Phys., 2006, 84, 1.

16 W. Wu, X. Chen, H. Hou, B. Liu and X. Li, Appl. Surf. Sci., 2018, 436, 80.

17 D. Holthusen, A. A. Brandt, J. M. Reichert and R. Horn, Soil Tillage Res., 2018, 117, 113.

18 K. S. Lim, N. Yahaya, N. M. Noor, S. N. F. M. M. Tahir and J. K. Paik, Ships Offshore Struc., 2017, 12, 991.

19 S. Wang, C. Du, X. Li, Z. Liu, M. Zhu and D. Zhang, Prog. Nat. Sci.: Mater. Int., 2015, 25, 242.

20 X. Zhang, K. Xiao, C. F. Dong, J. S. Wu, X. G. Li and Y. Z. Huang, Eng. Failure Anal., 2011, 18, 1981.

21 K. Xiao, X. Zhang, C. F. Dong, D. Wei, C. Wang and X. G. Li, J. Wuhan Univ. Technol., 2012, 27, 27. 
22 R. M. Cornell and U. Schwertmann, The iron oxides: structure, properties, reactions, occurrences and uses, Wiley-VCH, Weinheim, 2003.

23 W.-C. Reak, T. Kang, H.-T. Shon and Y. T. Kho, Electrochim. Acta, 2001, 46, 2321.

24 K. Hoffmann and M. Stratmann, Corros. Sci., 1993, 34, 1625. 29 U. R. Evans and C. A. Taylor, J. Corros. Sci. Eng., $1972,12,227$. 25 M. Stratmann, Corros. Sci., 1987, 27, 869.
26 T. Ujihara, K. Fujiwara, G. Sazaki and N. Usami, J. Cryst. Growth, 2002, 241, 387.

27 J. Vedelago, A. Quiroga and M. Valenta, Radiat. Eff. Defects Solids, 2014, 169, 845.

28 U. R. Evans, Corros. Sci., 1969, 9, 8131. 